\title{
ASSESSMENT OF THE ACCURACY OF A SOIL SALINITY MODEL FOR SHALLOW GROUNDWATER AREAS IN XINJIANG BASED ON ELECTROMAGNETIC INDUCTION
}

\author{
SONG, J. H. - SHI, X. Y. - CUI, J. - ZHU, Y. Q. - WANG, H. J. \\ Department of Resources and Environmental Science, Shihezi University \\ Shihezi, Xinjiang, PR China \\ (phone: +86-130-4054-6967) \\ *Corresponding author \\ e-mail: wanghaijiang@shzu.edu.cn; phone: +86-189-6382-7056 \\ (Received $9^{\text {th }}$ Apr 2019; accepted 19 th $^{\text {tun 2019) }}$
}

\begin{abstract}
Accurate and rapid assessment of soil salinity is a prerequisite for monitoring and management of soil salinization. Electromagnetic induction technology (EMI) has been broadly applied for scientific research and soil salinity monitoring. In this study, the path analysis method was used to analyze the influence of the soil properties of different soil layers and groundwater (GW) characteristics on apparent electrical conductivity (ECa) values measured at different heights of an EM38. The results showed that for all soil layers, the standard electrical conductivity of a saturated soil extract (ECe) was the most important factor affecting ECa measured at different heights. Both soil moisture content and GW characteristics (GW depth, GW conductivity) had an obvious effect on ECa, whereas the soil clay content had little effect. The reliability of ECe prediction models for different soil layers was improved to various degrees by the addition of soil water content and $\mathrm{GW}$ characteristics as auxiliary factors. The ECe prediction model was validated with the coefficient of determination $\left(\mathrm{R}^{2}\right)$ between the predicted and measured ECe values of each layer reaching more than 0.70 . The ECe prediction model can be used to accurately estimate any unsampled points in a study area.
\end{abstract}

Keywords: electromagnetic induction, soil profile, accurate interpretation, groundwater, soil properties

\section{Introduction}

Soil salinization is a global problem, affecting more than 930 million hectares of land, and the extent of the problem continues to increase (Rengasamy, 2006). High evaporation rates in arid and semi-arid areas increase the problem of soil salinization (Butcher et al., 2016; Li et al., 2014). Soil salinization negatively affects soil quality and sustainable agricultural development (Cassel et al., 2015). Land areas that are potentially impacted by soil salinization remain important resources for agricultural development. The key strategy to ensure the development and utilization of such land resources lies in the development of accurate and rapid soil salinity assessment and measurement techniques (Kasim et al., 2018; Abdu et al., 2007; Yao et al., 2010; Singh, 2018). At present, electromagnetic induction (EMI) is the most important and broadly-applied scientific method for measuring and assessing soil salinity. EMI is used to measure soil apparent electrical conductivity (ECa) to predict the salt content of the soil profile (Heil and Schmidhalter, 2017). Based on the existing research results, soil salinity (Dakak et al., 2017; Scudiero et al., 2016; Aboelsoud and AbdelRahman, 2017), soil moisture (Hossain et al., 2010; Huang et al., 2018), soil clay content (Doolittle et al., 2002; Triantafilis and Lesch, 2005), cation exchange capacity (Triantafilis and Santos, 2010; Suddth, 2005), organic matter content (Martinez et al., 2016; Bekele et al., 2005), soil temperature (Brevik et al., 2004), soil compaction 
(Krajco, 2007) and other major physical and chemical properties of the soil have an impact on its ECa. Therefore, the major factors affecting EMI of areas with different in soil properties differ considerably.

EM38 is a tool for rapid determination of ECa (McNeill, 1980). The assessment of soil salinity using ECa should be calibrated relative to the standard electrical conductivity of a saturated soil extract (ECe). Many scholars have used the EM38 to determine ECa to quantify and monitor soil salinity in arid and semi-arid irrigated agricultural areas (Jadoon et al., 2015; Ding and Yu, 2014; He et al., 2018). In the aforementioned research, almost all other soil physical and chemical properties were considered to be uniform; however, in the actual investigation process, the measurement accuracy of EM38 was often reduced due to uneven irrigation and differences in soil texture. A soil survey by Lesch and Corwin (2003) concluded that minimum water content should be at least $65 \%$ of the total capacity whenever possible. However, in arid and semi-arid regions, limited rainfall and irrigation water usually result inlarge differences in soil water (SW) content between plots. Therefore, the establishment of a calibration relationship between ECa and ECe depends on the soil type under specific field conditions and moisture status. In addition, the soil ECa increases with increasing clay content due to the fact that the clay content affects electromagnetic conductivity, whereas on the other hand soil clay content is closely related to cation exchange capacity (CEC) (Triantafilis and Lesch, 2005; Sudduth et al., 2005). In addition, partially exchangeable ions can produce ionic conductance, thus affecting ECa, and studies have shown that the variability of ECa conversion to $\mathrm{ECe}$ is greater in coarse-grained soils than in medium or fine-textured soils (McKenzie, 1993).

There have been many studies of the effects of SW content and soil salinity on ECa (Hanson and Kaita, 1997; Bennett et al., 2000; Wittler et al., 2006; Jiang et al., 2017). The results have shown that there is a linear relationship between SW content and ECa (Hanson and Kaita, 1997). ECa readings vary considerably with changes in SW content. Norman (1990) demonstrated that for clay soils, the water content of the soil profile should be greater than $20 \%$ to accurately obtain soil salinity values from the observed ECa data. Rahimian and Hasheminejhad (2011) found that the regression equation between ECah (horizontal mode) and ECav (vertical mode) and soil salinity obtained in the field with SW content of $35 \%$ was more reliable. Silberstein et al. (2007) found a significant correlation between ECa and groundwater (GW) level and GW conductivity $\left(\mathrm{R}^{2}=0.75, \mathrm{P}<0.001\right)$. Mankin and Karthikeyan $(2002)$ conducted research in the central and mid-south regions of Kansas, USA to distinguish between the saline exudation zone and non-exudation zone and assessed the extent of saline exudation by means of ECa measured by EM38.

In summary, although the relationship between soil ECe and $\mathrm{ECa}$ is reliable, the factors affecting different regions and different soil layers (e.g., moisture, clay content, GW depth and GW conductivity) differ. To construct an accurate interpretation model of soil profile salt content, the present study aimed to characterize the soil characteristics of the Xinjiang arid area by: (1) analysis of soil properties at different depths and determining the influence of GW characteristics on EM38 readings; (2) determine the dominant factors impacting on ECa determination, and establishing an accurate soil ECe interpretation model; (3) validate the precision and stability of the soil ECe interpretation model. 


\section{Materials and methods}

\section{Overview of research region}

The present study focused on the Karamay agricultural development area located within the lacustrine plain region on the southern side of the Dzungaria Basin in Xinjiang Province $\left(84^{\circ} 50^{\prime}-85^{\circ} 20^{\prime} \mathrm{E}\right.$ and $\left.45^{\circ} 22^{\prime}-45^{\circ} 40^{\prime} \mathrm{N}\right)$. The region has a desert climate with an annual mean temperature of $8{ }^{\circ} \mathrm{C}$ and an annual rainfall of $105.3 \mathrm{~mm}$. The average depth of GW in the area has risen by $6.90 \mathrm{~m}$ since 2000 due to improper irrigation methods, which has consequently resulted in soil salinization. To date, more than $66 \%$ of the area has been affected by soil salinization (Han et al., 2011).

The field within the Karamay agricultural development area of approximately 68 ha with the shallowest GW was chosen for the present study. Other factors considered were soil texture, salt status, vegetation types and irrigation methods. As shown in Figure 1, the GW depth (DGW) and quality were monitored from 11 positions. Sunflowers and matrimony vines planted in the field in 2016 were replaced with cotton in 2017. The crops were irrigated manually during their periods of growth using drip irrigation under mulch. Soil moisture content and GW characteristics were highly variable across the research region since the types of crops differ and the terrain is uneven, as shown in Table 2. Soil clay content at a depth of $1 \mathrm{~m}$ was spatially homogeneous, with an average value of approximately 56\%. On the other hand, serious soil salinization has occurred with a minimum and maximum ECe of $1.69 \mathrm{mS} \mathrm{cm}{ }^{-1}$ and $2.90 \mathrm{mS} \mathrm{cm}{ }^{-1}$, respectively. This relatively high salt content has restricted crop growth. Table 1 lists the monthly mean variations of DGW in the research region from 2013 to 2017, which show that DGW has been significantly influenced by agricultural irrigation before 2016 with an annual mean depth ranging from $0.78 \mathrm{~m}$ to $1.12 \mathrm{~m}$, and that DGW increased to a certain extent in 2016 and 2017 with a mean depth of $1.40 \mathrm{~m}$.

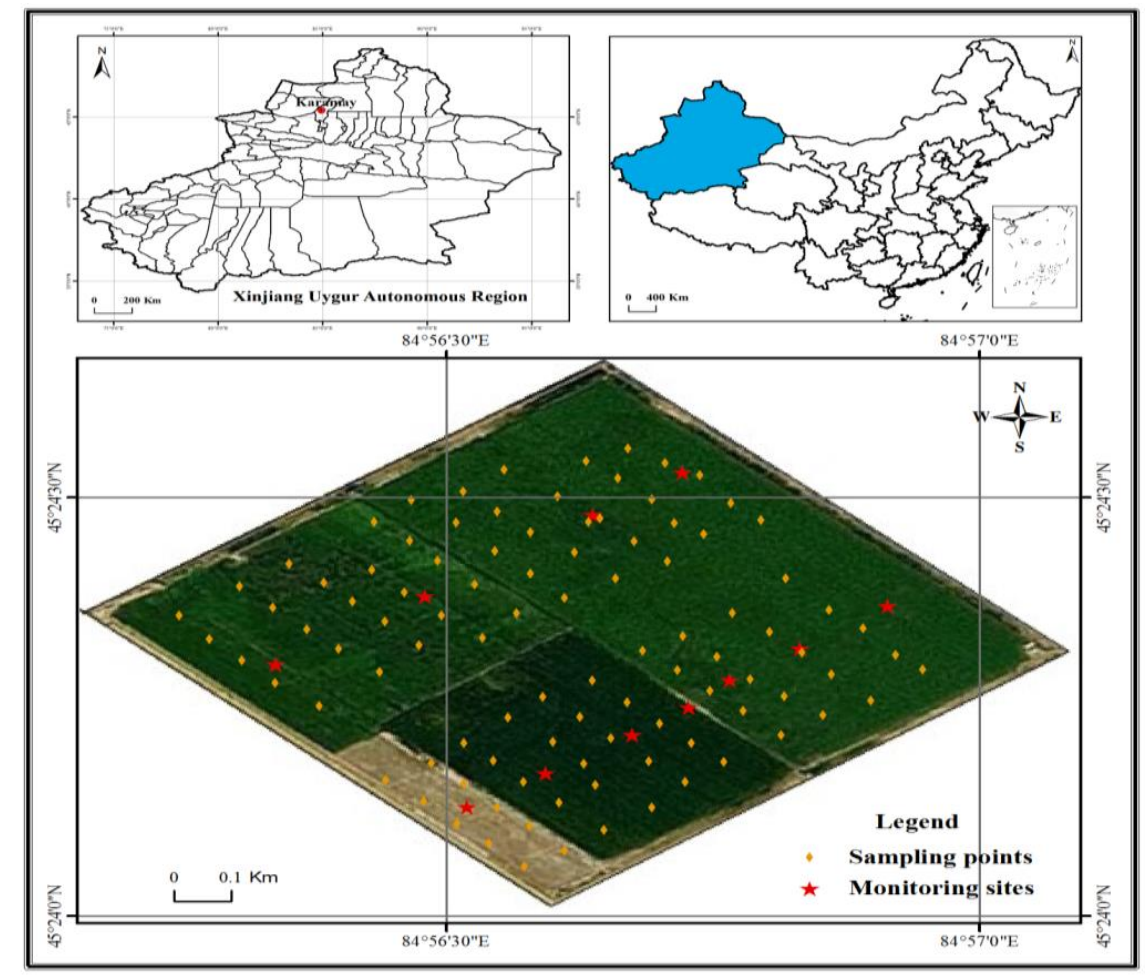

Figure 1. Spatial location of the experimental sites 
Table 1. Monthly mean change of groundwater level in the study area

\begin{tabular}{c|c|c|c|c|c|c|c|c}
\hline Years & June & July & August & September & October & November & Average & CV (\%) \\
\hline 2013 & 0.69 & 0.69 & 0.41 & 1.28 & 0.82 & 0.78 & 0.78 & 0.36 \\
2014 & 0.99 & 1.12 & 0.76 & 1.02 & 1.27 & 1.36 & 1.09 & 0.19 \\
2015 & 0.91 & 0.99 & 1.25 & 1.38 & 1.28 & 0.89 & 1.12 & 0.19 \\
2016 & 1.35 & 1.28 & 1.33 & 1.45 & 1.52 & 1.49 & 1.4 & 0.07 \\
2017 & 1.36 & 1.44 & 1.4 & 1.28 & 1.4 & 1.52 & 1.4 & 0.06 \\
\hline
\end{tabular}

\section{Data collection}

\section{Electromagnetic interference (EMI) data collection}

The EM38 had two receiver coils spaced at $0.5 \mathrm{~m}$ and $1 \mathrm{~m}$ from the transmitter coil. The transmitter coil was energised with an alternating current, generating a timevarying magnetic field in the earth. This magnetic field resulted in current flow in the soil, resulting in the generation of a secondary magnetic field. The strength of this secondary electromagnetic field was directly proportional to the ECa of the soil.

$$
E C a=4(H s / H p) / \omega \mu_{0} S^{2}
$$

where $\mathrm{ECa}$ is the apparent electrical conductivity, $\mathrm{Hs}$ and $\mathrm{Hp}$ are the secondary magnetic field and the primary magnetic field, respectively, $\omega=2 \pi \mathrm{f}$, where $\mathrm{f}$ is the transmission frequency $(\mathrm{Hz}), \mathrm{S}$ is the distance between the transmitting end and the receiving end $(\mathrm{m})$ and $\mu_{0}$ is the spatial magnetic field conduction coefficient.

In the present study, the EM38-MK2 instrument (Geonics Limited, On-tario, Canada) with effective investigation depths in the vertical and horizontal modes of $1.5 \mathrm{~m}$ and $0.75 \mathrm{~m}$ (McNeill, 1980), respectively and transmitting coil and receiving coil separated by $1 \mathrm{~m}$ was used to measure EMI data throughout the research region. According to previous studies, ECa is influenced by both soil properties and soil depth, and soil layers at different depths contribute to ECa at different degrees. Equations 2 and 3, representing density functions of the contributions of a soil layer at a certain depth to ECa in the vertical and horizontal modes, respectively, show that $20 \%$ of ECa in the horizontal mode is contributed by soil layers at depths $<1.2 \mathrm{~m}$ and $27 \%$ of ECa in the vertical mode is contributed by soil layers at depths $<1.8 \mathrm{~m}$. In the present study, the heights of EM38 during measurement were set at $1.30 \mathrm{~m}, 1.10 \mathrm{~m}, 0.90 \mathrm{~m}, 0.70 \mathrm{~m}$ and $0.50 \mathrm{~m}$ in sequence, corresponding to effective investigation depths of $0.20 \mathrm{~m}$, $0.40 \mathrm{~m}, 0.60 \mathrm{~m}, 0.80 \mathrm{~m}$ and $1.00 \mathrm{~m}$, respectively, in the vertical mode.

A total of 100 measurement positions were deployed using the systematic distribution method and the data were collected by EM38 in May, 2017. Before the measurement, EM38 was calibrated at a height of $1.5 \mathrm{~m}$, following which the values of ECa were measured at the heights of $1.30 \mathrm{~m}, 1.10 \mathrm{~m}, 0.90 \mathrm{~m}, 0.70 \mathrm{~m}$ and $0.50 \mathrm{~m}$ in the horizontal and vertical modes. In addition, the positions of the measurement points were recorded via GPS (Trimble, USA).

$$
\varphi^{v}(Z)=\frac{4 Z}{\left(4 Z^{2}+1\right)^{3 / 2}}
$$




$$
\varphi^{h}(z)=2-\frac{4 z}{\left(4 z^{2}+1\right)^{1 / 2}}
$$

where $\mathrm{z}$ denotes the depth of EM38 in the vertical direction.

\section{Collection and treatment of soil samples and GW}

To obtain soil property information, manual sampling procedures were implemented at the measurement points. The soil was separated into five layers: $0 \mathrm{~m}$ to $0.20 \mathrm{~m}$ (L1), $0.20 \mathrm{~m}$ to $0.40 \mathrm{~m}$ (L2), $0.40 \mathrm{~m}$ to $0.60 \mathrm{~m}(\mathrm{~L} 3), 0.60 \mathrm{~m}$ to $0.80 \mathrm{~m}$ (L4) and $0.80 \mathrm{~m}$ to $1.00 \mathrm{~m}$ (L5). Effective soil profiles totaling 90 were chosen and 450 soil samples were collected in total. Soil profiles totaling 60 were used to derive the salt content prediction model whereas the remaining 30 were used to validate the model.

The collected soil samples were mixed and then transported to the laboratory for characterization. The soil moisture content per unit mass $(\theta)$ was determined using the oven drying method. EC of 5:1 water to soil extract (ECe) was determined using a conductivity meter. Soil clay content $(\gamma)$ was determined using the hydrometer method.

The characteristic GW data were obtained from the 11 automated monitoring points. The monitored indices included GW depth (DGW), monitored by the DATA-5111 sensor (China), and GW EC (ECGW), monitored by the DATA-5102 water conductivity sensor (China). The sensors were set to collect data once every $2 \mathrm{~h}$.

\section{Data analysis method}

\section{Path analysis and its principles}

A number of factors need to be considered when deriving an accurate model for interpreting soil salt information based on EMI. At the same time, path analysis is a useful numerical analysis method suitable for determining the effects of multiple factors. Path analysis divides correlation coefficients into those exerting direct and indirect effects, which indicates the relative importance of the factors. Therefore, when studying the linear relationships between multiple correlated variables, path analysis can reveal the direct and indirect contributions of each independent variable to the dependent variable. With that in mind, path analysis was used in the present study to establish the contribution of soil properties and GW characteristics to ECa.

\section{Path coefficient}

Path analysis is a statistical multiple linear regression analysis method applied to standardized variables and path coefficients are partial regression coefficients for standardized variables. The path coefficient of an independent variable reflects its relative magnitude and property in relation to the dependent variable.

Assuming the existence of a linear relationship between the dependent variable $y$ and the independent variables $x_{i}(\mathrm{i}=1,2,3, \ldots, \mathrm{n})$, the regression equation can be written as:

$$
y=b_{0}+b_{1} x_{1}+b_{2} x_{2}+\cdots+b_{n} x_{n}
$$

Then, based on the standardized multiple linear regression equation, the canonical equations can be derived as: 


$$
\left\{\begin{array}{ccccccccc}
P_{y x_{1}} & + & r_{x_{1} x_{2}} P_{y x_{2}} & + & \cdots & + & r_{x_{1} x_{n}} P_{y x_{n}} & = & r_{x_{1} y} \\
r_{x_{1} x_{2}} P_{y x_{2}} & + & P_{y x_{2}} & + & \cdots & + & r_{x_{2} x_{n}} P_{y x_{n}} & = & r_{x_{2} y} \\
\vdots & \vdots & \vdots & \vdots & \cdots & \vdots & \vdots & \vdots & \vdots \\
r_{x_{n} x_{1}} P_{y x_{1}} & + & r_{x_{n} x_{2}} P_{y x_{2}} & + & \cdots & + & P_{y x_{n}} & = & r_{x_{n} y}
\end{array}\right.
$$

Equation 5 can be transformed into a normal matrix equation as:

$$
\left[\begin{array}{cccc}
1 & r_{x_{1} x_{2}} & \cdots & r_{x_{1} x_{n}} \\
r_{x_{2} x_{1}} & 1 & \cdots & r_{x_{2} x_{n}} \\
\vdots & \vdots & \ddots & \vdots \\
r_{x_{n} x_{1}} & r_{x_{n} x_{2}} & \cdots & 1
\end{array}\right]\left[\begin{array}{c}
P_{y x_{1}} \\
P_{y x_{2}} \\
\vdots \\
P_{y x_{n}}
\end{array}\right]=\left[\begin{array}{c}
r_{x_{1} y} \\
r_{x_{2} y} \\
\vdots \\
r_{x_{n} y}
\end{array}\right]
$$

where $r_{x_{i} x_{j}}$ is the simple correlation coefficient of $x_{i}$ and $x_{j}$, and $r_{x_{i} y}$ is the simple correlation coefficient of $x_{i}$ and $y$. The path coefficient $P_{y x_{i}}$ can be obtained by solving Equation 5. $r_{x_{i} x_{j}} P_{y x_{i}}$ represents the indirect path coefficient of $x i$ to $y$ via $x_{j}$.

\section{Contribution rates of variables}

The influencing factors can be ordered according to their path coefficients. Furthermore, since the contributions of the variables are calculated from their direct path coefficients, the contribution rates of the influencing factors to ECa can also be calculated:

$$
\eta=|a| /(|a|+|b|+|c|+|d|+\cdots)
$$

where $\mathrm{a}, \mathrm{b}, \mathrm{c}, \mathrm{d}$... denote the direct path coefficients of the corresponding variables and $\eta$ denotes the contribution rate of the first variable.

\section{Derivation of the ECe prediction model}

Path analysis was used to analyze how soil properties (including $\theta, \gamma$ and ECe) and GW characteristics are related to ECa as measured by EM38 at different heights. The non-salt factors with high contribution rates to $\mathrm{ECa}$ were then chosen as independent variables with soil conductivity as the dependent variable. The optimal soil salt interpretation model was then derived using multiple linear regression (MLR). The data analysis and model derivation were conducted using SPSS 20.0 (IBM, USA), and the figures and tables were compiled using Sigmaplot 12.0 (Systat Software, USA).

\section{Model validation}

The reserved 30 soil profiles were used to validate the reliability of the ECe prediction model using three indices: mean error (ME), root mean square error (RMSE) and coefficient of determination $\left(\mathrm{R}^{2}\right)$.

Among them:

Mean Error (ME): 


$$
M E=\frac{1}{N} \sum_{i=1}^{N}\left|x_{i}-y_{i}\right|
$$

Root Mean Square Error (RMSE):

$$
\mathrm{RMSE}=\sqrt{\frac{1}{\mathrm{~N}} \sum_{i=1}^{N}\left(x_{i}-y_{i}\right)^{2}}
$$

where $x i$ is the interpreted value, $\mathrm{y}_{\mathrm{i}}$ is the observed value and $\mathrm{N}$ is the number of data points.

When using the test model, root mean squared error (RMSE) was always used for statistical analysis of conformity between simulated values and measured values. The smaller the RMSE value, the better the consistency and the smaller the deviation between simulated values and measured values, and thus the more accurate and reliable the model.

\section{Results and discussion}

\section{Data analysis}

Table 2 lists the soil properties and GW characteristics (including ECGW and DGW) of different soil layers and readings of EM38 at different heights. The soil texture in the research region ranged from heavy loam to light clay, and the soil profile clay content was distributed relatively evenly. At L1-L5, $\gamma$ ranged from $49 \%$ to $62 \%$, with the maximum in L3. $\theta$ showed a trend of increasing from the top soil layer $(8 \%)$ to the bottom soil layer (25\%) and was not evenly distributed in the soil profiles. According Lesch and Corwin (2003), if $\theta$ is far less than field moisture capacity, the spatial variation in $\theta$ is likely to become the most important factor contributing to EM data, even if salt content shows significant spatial variation. Norman (1990) found that soil profile $\theta$ should be greater than $20 \%$ in clay soil to accurately estimate soil salt content according to measured EM data. Given the above information, the $\theta$ of the study area in the present study could preclude the development of an effective soil salt prediction model. At the same time, ECe showed a clear variation among different soil layers, with average ECe of each layer ranging from $1.69 \mathrm{mS} \mathrm{cm}^{-1}$ to $2.9 \mathrm{mS} \mathrm{cm}^{-1}$. At L1-L4, the coefficient of variation of ECe decreased from $60.69 \%$ to $34.66 \%$ with increasing soil depth, whereas at L5, the coefficient of variation of ECe increased to 50.69\%. This illustrated the complex spatial distribution of ECe. DGW was highly variable across the region with a minimum, maximum and average DGW of $1.12 \mathrm{~m}, 1.38 \mathrm{~m}$ and $1.34 \mathrm{~m}$, respectively, and ECGW ranged from $35.8 \mathrm{mS} \mathrm{cm}^{-1}$ to $62.8 \mathrm{mS} \mathrm{cm}^{-1}$ with an average of $2.36 \mathrm{mS} \mathrm{cm}{ }^{-1}$ due to high GW mineralization and poor water quality. Therefore, the moisture and salt contents of the soil profiles could be influenced by the shallow depths and high salt content of GW, thereby influencing EM38 measurements.

Corwin and Rhoades (1982) derived the EC of the soil profile in the vertical direction based on the linear hypothesis and using the values of ECa measured by EMI at different heights, a method which has been proven to effectively improve the accuracy of predicting soil salt using EM38 (Cook and Walker, 1992). In the present study, the EM38 readings decreased with increasing height. The signals received by 
EM38 were generated mainly by the top soil layer and the contribution of the bottom soil layer to the EM38 readings decreased with increasing soil depth (McNeil, 1990). Soil at depths of $0 \mathrm{~m}-1.50 \mathrm{~m}$ accounted for $70 \%$ of the readings in the vertical mode, and with increasing EM38 height, the effective investigation depth decreased (Abdu et al., 2007). In addition, the aboveground atmosphere with an ECa of 0 made no contribution to EM38 readings (Misra and Padhi, 2014). The aforementioned facts explain the reason for a noticeable decrease in EM38 readings as height increased. Huang et al. (2015) found that ECa variations decreased significantly as height increased, which is consistent with the results of the present study.

Table 2. Summary characteristics of soil properties at various soil depths, groundwater properties, and EM38 measurements collected invarious layers

\begin{tabular}{|c|c|c|c|c|c|c|c|}
\hline Soil layer & & $\mathbf{N}$ & Max & Min & Average & Standard deviation & $\mathbf{C V}$ \\
\hline \multirow{5}{*}{$0-0.20$} & EMh1.30 & 60 & 92 & 9 & 47.5 & 22.41 & $47.18 \%$ \\
\hline & EMv1.30 & 60 & 170 & 21 & 94.88 & 43.86 & $46.23 \%$ \\
\hline & $\mathrm{ECe} / \mathrm{mS} \mathrm{cm}^{-1}$ & 60 & 6.89 & 0.5 & 2.9 & 1.76 & $60.69 \%$ \\
\hline & $\theta / \%$ & 60 & 0.18 & 0.08 & 0.13 & 0.02 & $15.38 \%$ \\
\hline & $\gamma / \%$ & 60 & 0.82 & 0.16 & 0.49 & 0.16 & $32.65 \%$ \\
\hline \multirow{5}{*}{$0.20-0.40$} & EMh1.10 & 60 & 131 & 15 & 66.93 & 34.25 & $51.17 \%$ \\
\hline & EMv1.10 & 60 & 230 & 25 & 121.15 & 56.55 & $46.68 \%$ \\
\hline & $\mathrm{ECe} / \mathrm{mS} \mathrm{cm}^{-1}$ & 60 & 4 & 0.5 & 1.99 & 0.78 & $39.24 \%$ \\
\hline & $\theta / \%$ & 60 & 0.22 & 0.09 & 0.16 & 0.03 & $21.16 \%$ \\
\hline & $\gamma / \%$ & 60 & 0.85 & 0.10 & 0.53 & 0.20 & $37.29 \%$ \\
\hline \multirow{5}{*}{$0.40-0.60$} & EMh0.90 & 60 & 195.00 & 26.00 & 92.48 & 48.93 & $52.91 \%$ \\
\hline & EMv0.90 & 60 & 268.00 & 37.00 & 152.88 & 65.56 & $42.88 \%$ \\
\hline & $\mathrm{ECe} / \mathrm{mS} \mathrm{cm}^{-1}$ & 60 & 3.52 & 0.85 & 2.05 & 0.73 & $35.63 \%$ \\
\hline & $\theta / \%$ & 60 & 0.25 & 0.11 & 0.18 & 0.03 & $17.62 \%$ \\
\hline & $\gamma / \%$ & 60 & 0.84 & 0.27 & 0.62 & 0.18 & $29.14 \%$ \\
\hline \multirow{5}{*}{$0.60-0.80$} & EMh0.70 & 60 & 360 & 35 & 137.75 & 77.60 & $56.33 \%$ \\
\hline & EMv0.70 & 60 & 472 & 56 & 209.03 & 106.57 & $50.98 \%$ \\
\hline & $\mathrm{ECe} / \mathrm{mS} \mathrm{cm}^{-1}$ & 60 & 3.5 & 0.68 & 1.74 & 0.60 & $34.66 \%$ \\
\hline & $\theta / \%$ & 60 & 0.24 & 0.1 & 0.18 & 0.04 & $20.12 \%$ \\
\hline & $\gamma / \%$ & 60 & 0.84 & 0.22 & 0.59 & 0.21 & $35.25 \%$ \\
\hline \multirow{7}{*}{$0.80-1.00$} & EMh0.50 & 60 & 514 & 58 & 210.73 & 120.56 & $57.21 \%$ \\
\hline & EMv0.50 & 60 & 636 & 84 & 282.50 & 140.52 & $49.74 \%$ \\
\hline & $\mathrm{ECe} / \mathrm{mS} \mathrm{cm}^{-1}$ & 60 & 4.26 & 0.42 & 1.69 & 0.85 & $50.69 \%$ \\
\hline & $\theta / \%$ & 60 & 0.25 & 0.13 & 0.18 & 0.03 & $16.82 \%$ \\
\hline & $\gamma / \%$ & 60 & 0.88 & 0.13 & 0.59 & 0.22 & $37.28 \%$ \\
\hline & ECGW $/ \mathrm{mS} \mathrm{cm}^{-1}$ & 7 & 62.8 & 35.8 & 52.36 & 10.06 & $19.21 \%$ \\
\hline & $\mathrm{DGW} / \mathrm{m}$ & 7 & 1.38 & 1.12 & 1.34 & 11.71 & $8.72 \%$ \\
\hline
\end{tabular}

Analysis of factors influencing ECa in different soil layers

Factors influencing ECa as measured by EM38 at a height of 1.30 m (EM1.30)

Path analysis in two modes was used to determine the factors influencing ECa (EMh1.30 and EMv1.30) and their degrees of influence. When conducting path analysisat L1, $\theta, \gamma$, ECe, ECGW and DGW were regarded as independent variables and EMh1.30 and EMv1.30 were regarded as dependent variables. Table 3 lists the results 
of path analysis used to determine the factors influencing ECa (i.e., EMh1.30 and EMv1.30) measured at a height of $1.30 \mathrm{~m}$. W) except for ECe, indicating that $\theta$ had a certain degree of influence on EMv1.30 at L1. ECe showed the best correlation with EMh1.30 and EMv1.30 at L1 measured at a height of $1.30 \mathrm{~m}$, with the correlation being extremely significant at the $\mathrm{P}=0.01$ level with correlation coefficients of 0.86 and 0.83 , respectively. On the other hand, no significant correlations were evident between ECa and $\theta, \gamma, \mathrm{ECGW}$ or DGW, among which the correlation between ECa and $\theta$ was the lowest $(\mathrm{R}<0.10)$. According to the results, the order of independent variables in regards to their influence on EMv1.30 at L1 was: ECe $>\theta>\gamma>\mathrm{ECGW}>\mathrm{DGW}$. The order of independent variables in regards to their influence on EMh1.30 was $\mathrm{ECe}>\mathrm{DGW}>\gamma>\theta>\mathrm{ECGW}$. Therefore, since ECe had the largest effect on both EMh1.30 and EMv1.30 at L1, it can be concluded that ECe was the most important factor influencing ECa as measured by EM38 at a height of $1.30 \mathrm{~m}$. Thus, ECe can be used to ECa. Among the other influencing factors, the influence of DGW on EMh1.30 was larger than that of $\theta, \gamma$ or ECGW. Generally speaking, with EM38 height set to $1.30 \mathrm{~m}$, the effective investigation depth for EMh1.30 was not sufficiently deep to reach the soil surface. However, an extremely significant linear relationship $(\mathrm{P}<0.001)$ existed between EMh1.30 and EMv1.30, and a significant correlation $(\mathrm{R}=-0.432$, $\mathrm{P}<0.01)$ existed between DGW and ECe at L1. Therefore, it is likely that the influence of DGW on ECe was responsible for the correlation between DGW and EMh1.30. On the other hand, the contribution of $\theta$ to EMv1.30 was $10.93 \%$, larger than those of the other influencing factors $(\gamma, \mathrm{ECGW}$ and DG).

Table 3. Path coefficients between influence factors to EM38 values at $1.30 \mathrm{~m}$ above the ground of 0-0.20 m

\begin{tabular}{c|c|c|c|c|c|c|c|c}
\hline $\begin{array}{c}\text { Dependent } \\
\text { variable }\end{array}$ & Variable & ECe & $\boldsymbol{\theta}$ & $\boldsymbol{\gamma}$ & $\mathbf{E C G W}$ & $\mathbf{D G W}$ & $\begin{array}{c}\text { Contribution } \\
\text { rate }\end{array}$ & $\begin{array}{c}\text { Correlation } \\
\text { coefficient } \\
\text { with EM }\end{array}$ \\
\hline \multirow{5}{*}{ EMv1.30 } & $\mathrm{ECe}$ & $\mathbf{0 . 7 8 8 0}$ & -0.0013 & 0.0291 & 0.0233 & 0.0241 & $65.78 \%$ & $0.86^{* *}$ \\
& $\boldsymbol{\gamma}$ & -0.0055 & $\mathbf{0 . 1 3 1 0}$ & -0.0302 & -0.0089 & 0.0134 & $10.93 \%$ & 0.10 \\
& $\mathrm{ECGW}$ & -0.2017 & -0.0355 & $\mathbf{- 0 . 1 1 2 0}$ & -0.0155 & -0.0073 & $9.35 \%$ & -0.30 \\
& $\mathrm{DGW}$ & -0.3404 & -0.0320 & -0.0146 & -0.0488 & $\mathbf{- 0 . 0 5 6 0}$ & $4.67 \%$ & -0.31 \\
\hline \multirow{5}{*}{ EMh1.30 } & $\mathrm{ECe}$ & $\mathbf{0 . 7 5 3 0}$ & -0.0006 & 0.0218 & 0.0036 & 0.0538 & $72.68 \%$ & $0.83^{* *}$ \\
& $\theta$ & -0.0053 & $\mathbf{0 . 0 5 7 0}$ & -0.0227 & -0.0014 & 0.0300 & $5.50 \%$ & 0.06 \\
& $\gamma$ & -0.1928 & 0.0154 & $\mathbf{- 0 . 0 8 4 0}$ & -0.0024 & -0.0163 & $8.11 \%$ & -0.28 \\
& $\mathrm{ECGW}$ & -0.1596 & 0.0044 & -0.0117 & $\mathbf{- 0 . 0 1 7 0}$ & -0.0550 & $1.64 \%$ & -0.24 \\
& $\mathrm{DGW}$ & -0.3253 & -0.0139 & -0.0113 & -0.0075 & $\mathbf{- 0 . 1 2 5 0}$ & $12.07 \%$ & -0.48 \\
\hline
\end{tabular}

EMh1.30 - EM38 values of apparent electrical conductivity in horizontal operation mode; EMv1.30EM38 values of apparent conductivity in vertical operation mode; ECe-soil electrical conductivity; $\theta$ - soil moisture; $\gamma$-soil clay content; ECGW-groundwater conductivity; DGW-groundwater level; ** indicates significant at 0.01 level, * indicates significant at 0.05 level. Bold font indicates direct path coefficient of corresponding factor

Factors influencing EC as measured by EM38 at a height of $1.10 \mathrm{~m}$ (EM1.10)

When conducting path analysis at L2, $\theta, \gamma$, ECe, ECGW and DGW were regarded as independent variables whereas EMh1.10 and EMv1.10 were regarded as dependent 
variables. Table 4 lists the results of path analysis used to determine the factors influencing ECa (i.e., EMh1.10 and EMv1.10) measured at a height of $1.10 \mathrm{~m}$. ECe also had a significant correlation with EMh1.10 and EMv1.10 measured at a height of $1.10 \mathrm{~m}$ in the two modes at L2, with correlation coefficients of 0.89 and $0.86(\mathrm{P}<0.01)$, respectively. At L2, the correlations between $\theta$ and EMh1.10 and $\theta$ and EMv1.10 were $0.53(\mathrm{P}<0.05)$ and $0.67(\mathrm{P}<0.01)$, respectively, indicating that $\theta$ had an influence on $\mathrm{ECa}$ at L2. On the other hand, no significant correlations were evident between ECa measured at a height of $1.10 \mathrm{~m}$ and $\gamma, \mathrm{ECGW}$ or DGW. According to the results, the order of the independent variables according to their influence on EMv1.10 at L2 was: $\mathrm{ECe}>\theta>\mathrm{DGW}>\mathrm{ECGW}>\gamma$. The order of the independent variables according to their influence on EMh1.10 was: ECe $>\theta>$ DGW $>$ ECGW $>\gamma$. Therefore, since ECe also had the largest influence on both EMh1.10 and EMv1.10 at L2, it can be concluded that ECe was the most important factor influencing ECa as measured by EM38 at a height of $1.30 \mathrm{~m}$. Among the other factors, the contribution rates of $\theta$ to EMh1.10 and EMv1.10 (7.85\% and 25.16\%, respectively) were larger than those of DGW, $\gamma$, or ECGW, indicating that $\theta$ had a relatively significant influence on the data measured by EM38 at L2.

Table 4. Path coefficients between influence factors to EM38 values at $1.10 \mathrm{~m}$ above the ground of $0.20 \sim 0.40 \mathrm{~m}$

\begin{tabular}{c|c|c|c|c|c|c|c|c}
\hline $\begin{array}{c}\text { Dependent } \\
\text { variable }\end{array}$ & Variable & ECe & $\boldsymbol{\theta}$ & $\boldsymbol{\gamma}$ & $\mathbf{E C G W}$ & $\mathbf{D G W}$ & $\begin{array}{c}\text { Contribution } \\
\text { rate }\end{array}$ & $\begin{array}{c}\text { Correlation } \\
\text { coefficient } \\
\text { with EM }\end{array}$ \\
\hline \multirow{5}{*}{ EMv1.10 } & ECe & $\mathbf{0 . 8 2 7 0}$ & 0.0397 & -0.0001 & 0.0043 & 0.0154 & $82.21 \%$ & $0.89^{* *}$ \\
& $\theta$ & 0.4160 & $\mathbf{0 . 0 7 9 0}$ & 0.0007 & 0.0068 & 0.0246 & $7.85 \%$ & $0.53^{*}$ \\
& $\gamma$ & -0.0298 & 0.0284 & $\mathbf{0 . 0 0 2 0}$ & -0.0017 & -0.0002 & $0.20 \%$ & 0.001 \\
& ECGW & -0.0794 & -0.0119 & 0.0001 & $\mathbf{- 0 . 0 4 5 0}$ & -0.0231 & $4.47 \%$ & -0.16 \\
& DGW & -0.2407 & -0.0367 & 0.0000 & -0.0196 & $\mathbf{- 0 . 0 5 3 0}$ & $5.27 \%$ & $-0.35^{*}$ \\
\hline \multirow{5}{*}{ EMh1.10 } & ECe & $\mathbf{0 . 6 8 8 0}$ & 0.1393 & -0.0002 & 0.0050 & 0.0230 & $62.49 \%$ & $0.86^{* *}$ \\
& $\theta$ & 0.3461 & $\mathbf{0 . 2 7 7 0}$ & 0.0018 & 0.0078 & 0.0367 & $25.16 \%$ & $0.67^{* *}$ \\
& $\gamma$ & -0.0248 & 0.0997 & $\mathbf{0 . 0 0 5 0}$ & -0.0019 & -0.0003 & $0.45 \%$ & 0.08 \\
& ECGW & -0.0660 & -0.0416 & 0.0002 & $\mathbf{- 0 . 0 5 2 0}$ & -0.0344 & $4.72 \%$ & -0.19 \\
& DGW & -0.2002 & -0.1285 & 0.0000 & -0.0227 & $\mathbf{- 0 . 0 7 9 0}$ & $7.18 \%$ & $-0.43^{* *}$ \\
\hline
\end{tabular}

EMh1.10 - EM38 values of apparent electrical conductivity in horizontal operation mode; EMv1.10 EM38 values of apparent conductivity in vertical operation mode; ECe - soil electrical conductivity; $\theta$ —soil moisture; $\gamma$ —soil clay content; ECGW—groundwater conductivity; DGW—groundwater level; ** indicates significant at 0.01 level, * indicates significant at 0.05 level. Bold font indicates direct path coefficient of corresponding factor

According to the density functions of EM38, i.e., Equations 3 and 4, at an EM38 height $<1.10 \mathrm{~m}$, EMv1.10 was mainly influenced by soil properties at L1-L2. According to the present results, ECe at L2 had the largest influence on EMv1.10 and EMh1.10, with the second-most important factor being $\theta$ with a rate of contribution of 25.16\%. Huang et al. (2015) found that at an EM38 height of $1.00 \mathrm{~m}$, ECe showed the best correlations with EMh and EMv in the $0.15 \mathrm{~m}-0.30 \mathrm{~m}$ soil layer $(\mathrm{R}=0.750$ and $\mathrm{R}=0.773$, respectively), which supports the reliability of the results of the present 
study. In addition, the correlations of ECe with EMh and EMv at L2 in the present study were even stronger ( $R=0.86$ and $R=0.89$, respectively).

Factors influencing ECa as measured by EM38 at a height of $0.90 \mathrm{~m}$ (EM0.90)

When conducting path analysis at L3, $\theta, \gamma$, ECe, ECGW and DGW were regarded as independent variables, whereas and EMh0.90 and EMv0.90 were regarded as dependent variables. Table 5 lists the results of path analysis used to determine the factors influencing ECa (i.e., EMh0.90 and EMv0.90) measured at a height of $0.90 \mathrm{~m}$. At L3, ECe showed significant correlations with both EMh0.90 and EMv0.90, with correlation coefficients of 0.86 for both $(\mathrm{P}<0.01) . \theta$ and DGW also showed significant correlations with EM0.90 $(\mathrm{P}<0.05)$ at L3, indicating that $\theta$ and DGW influenced ECa measured at a height of $0.90 \mathrm{~m}$. According to the results, the rates of contribution of ECe to EMh0.90 and EMv0.90 at L3 were the highest among all the factors at $65.79 \%$ and $56.12 \%$, respectively. The rates of contribution of ECGW and DGW to EMv0.90 were $12.75 \%$ and $10.64 \%$, respectively, and they also had relatively significant influences on EMh0.90 with rates of contribution of $10.23 \%$ and $13.55 \%$, respectively.

Table 5. Path coefficients between influence factors to EM38 values at $0.90 \mathrm{~m}$ above the ground of $0.40 \sim 0.60 \mathrm{~m}$

\begin{tabular}{c|c|c|c|c|c|c|c|c}
\hline $\begin{array}{c}\text { Dependent } \\
\text { variable }\end{array}$ & Variable & ECe & $\boldsymbol{\theta}$ & $\boldsymbol{\gamma}$ & $\mathbf{E C G W}$ & $\mathbf{D G W}$ & $\begin{array}{c}\text { Contribution } \\
\text { rate }\end{array}$ & $\begin{array}{c}\text { Correlation } \\
\text { coefficient } \\
\text { with EM }\end{array}$ \\
\hline & $\mathbf{0 . 7 4 8 0}$ & 0.0686 & 0.0019 & 0.0049 & 0.0380 & $65.79 \%$ & $0.86^{* *}$ & $\mathbf{0 . 7 4 8 0}$ \\
& 0.4937 & $\mathbf{0 . 1 0 4 0}$ & 0.0066 & -0.0038 & 0.0276 & $9.15 \%$ & $0.63^{* *}$ & 0.4937 \\
EMv0.90 & 0.0741 & 0.0363 & $\mathbf{0 . 0 1 9 0}$ & -0.0067 & -0.0096 & $1.67 \%$ & 0.11 & 0.0741 \\
& -0.0254 & 0.0027 & 0.0009 & $\mathbf{- 0 . 1 4 5 0}$ & -0.0528 & $12.75 \%$ & -0.22 & -0.0254 \\
& -0.2349 & -0.0237 & 0.0015 & -0.0632 & $\mathbf{- 0 . 1 2 1 0}$ & $10.64 \%$ & $-0.44^{* *}$ & -0.2349 \\
\hline & $\mathbf{0 . 6 4 2 0}$ & 0.1452 & 0.0010 & 0.0040 & 0.0487 & $56.12 \%$ & $0.84^{* *}$ & $\mathbf{0 . 6 4 2 0}$ \\
& 0.4237 & $\mathbf{0 . 2 2 0 0}$ & 0.0035 & -0.0030 & 0.0353 & $19.23 \%$ & $0.68^{* *}$ & 0.4237 \\
EMh0.90 & 0.0614 & 0.0768 & $\mathbf{0 . 0 1 0 0}$ & -0.0054 & -0.0122 & $0.87 \%$ & 0.13 & 0.0614 \\
& -0.0218 & 0.0057 & 0.0005 & $\mathbf{- 0 . 1 1 7 0}$ & -0.0676 & $10.23 \%$ & -0.20 & -0.0218 \\
& -0.2015 & -0.0502 & 0.0008 & -0.0510 & $\mathbf{- 0 . 1 5 5 0}$ & $13.55 \%$ & $-0.46^{* *}$ & -0.2015 \\
\hline
\end{tabular}

EMh0.90-EM38 values of apparent electrical conductivity in horizontal operation mode; EMv0.90EM38 values of apparent conductivity in vertical operation mode; ECe-soil electrical conductivity; $\theta$ - soil moisture; $\gamma$-soil clay content; ECGW - groundwater conductivity; DGW - groundwater level; ** indicates significant at 0.01 level, * indicates significant at 0.05 level. Bold font indicates direct path coefficient of corresponding factor

Factors influencing ECa as measured by EM38 at a height of $0.70 \mathrm{~m}$ (EM0.70)

When conducting path analysis at L4, $\theta, \gamma$, ECe, ECGW and DGW were regarded as independent variables and EMh0.70 and EMv0.70 were regarded as dependent variables. Table 6 shows the results of path analysis to determine the factors influencing ECa (i.e., EMh0.70 and EMv0.70) measured at a height of $0.70 \mathrm{~m}$. At L4, ECe showed significant correlations with both EMh0.70 and EMv0.70, with correlation coefficients of 0.81 and $0.80(\mathrm{P}<0.01)$, respectively. $\theta$ and $\mathrm{DGW}$ also showed significant correlations with EM0.70 $(\mathrm{P}<0.05)$ at $\mathrm{L} 4$, indicating that $\theta$ and DGW influenced ECa 
measured at a height of $0.70 \mathrm{~m}$. According to the results, the rates of contribution of ECe to EMh0.70 and EMv0.70 at L4 were $49.26 \%$ and $39.49 \%$, respectively. On the other hand, $\theta$ and DGW had relatively significant influences on EMh0.70 and EMv0.70 with rates of contribution of $16.64 \%$ and $24.14 \%$ and $22.62 \%$ and $18.55 \%$, respectively. Therefore, it can be inferred that as the height of EM38 decreased, the rates of contribution of ECe to EMh0.70 and EMv0.70 decreased with increasing soil depth, whereas the contribution rates of the other factors increased.

Table 6. Path coefficients between influence factors to EM38 values at $0.70 \mathrm{~m}$ above the ground of $0.60 \sim 0.80 \mathrm{~m}$

\begin{tabular}{c|c|c|c|c|c|c|c|c}
\hline $\begin{array}{c}\text { Dependent } \\
\text { variable }\end{array}$ & Variable & ECe & $\boldsymbol{\theta}$ & $\boldsymbol{\gamma}$ & ECGW & DGW & $\begin{array}{c}\text { Contribution } \\
\text { rate }\end{array}$ & $\begin{array}{c}\text { Correlation } \\
\text { coefficient } \\
\text { with EM }\end{array}$ \\
\hline & $\mathbf{0 . 6 0 1 0}$ & 0.1153 & 0.0001 & 0.0082 & 0.0845 & $49.26 \%$ & $0.81^{* *}$ & $\mathbf{0 . 6 0 1 0}$ \\
& 0.3414 & $\mathbf{0 . 2 0 3 0}$ & -0.0009 & -0.0150 & 0.0560 & $16.64 \%$ & $0.58^{* *}$ & 0.3414 \\
EMv0.70 & -0.0126 & 0.0345 & $\mathbf{- 0 . 0 0 5 0}$ & -0.0019 & -0.0028 & $0.41 \%$ & 0.01 & -0.0126 \\
& -0.0367 & 0.0225 & -0.0001 & $\mathbf{- 0 . 1 3 5 0}$ & -0.1203 & $11.07 \%$ & -0.27 & -0.0367 \\
& -0.1839 & -0.0412 & -0.0001 & -0.0589 & $\mathbf{- 0 . 2 7 6 0}$ & $22.62 \%$ & $-0.56^{* *}$ & -0.1839 \\
\hline & $\mathbf{0 . 5 3 0 0}$ & 0.1840 & 0.0024 & 0.0077 & 0.0762 & $39.49 \%$ & $0.80^{* *}$ & $\mathbf{0 . 5 3 0 0}$ \\
& 0.3010 & $\mathbf{0 . 3 2 4 0}$ & -0.0192 & -0.0140 & 0.0505 & $24.14 \%$ & $0.64^{* *}$ & 0.3010 \\
EMh0.70 & -0.0111 & 0.0551 & $\mathbf{- 0 . 1 1 3 0}$ & -0.0018 & -0.0025 & $8.42 \%$ & -0.07 & -0.0111 \\
& -0.0323 & 0.0360 & -0.0016 & $\mathbf{- 0 . 1 2 6 0}$ & -0.1086 & $9.39 \%$ & -0.23 & -0.0323 \\
& -0.1622 & -0.0658 & -0.0011 & -0.0549 & $\mathbf{- 0 . 2 4 9 0}$ & $18.55 \%$ & $-0.53 * *$ & -0.1622 \\
\hline
\end{tabular}

EMh0.70 - EM38 values of apparent electrical conductivity in horizontal operation mode; EMv0.70EM38 values of apparent conductivity in vertical operation mode; ECe - soil electrical conductivity; $\theta$ - soil moisture; $\gamma$ — soil clay content; ECGW—groundwater conductivity; DGW—groundwater level; ** indicates significant at 0.01 level, * indicates significant at 0.05 level. Bold font indicates direct path coefficient of corresponding factor

Factors influencing ECa as measured by EM38 at a height of $0.50 \mathrm{~m}$ (EM0.50)

When conducting the path analysis at L5, $\theta, \gamma$, ECe, ECGW and DGW were regarded as the independent variables and EMh0.50 and EMv0.50 were regarded as dependent variables. Table 7 lists the results of path analysis conducted to determine the factors influencing ECa (i.e., EMh0.50 and EMv0.50) measured at a height of $0.50 \mathrm{~m}$. At L5, ECe showed significant correlations with both EMh0.50 and EMv0.50 with correlation coefficients of 0.80 and $0.78(\mathrm{P}<0.01)$, respectively. $\theta$ and DGW also showed significant correlations with ECa $(\mathrm{P}<0.05)$, possibly because ECa at L5 had shown a significant correlation with DGW (REC-Dgw $=0.34^{*}, \mathrm{P}<0.05$ ), which indirectly imposed an influence on EM0.50 through ECe. According to the results, the rates of contribution of ECe to EMh0.50 and EMv0.50 at L5 were $36.98 \%$ and $32.58 \%$, respectively. On the other hand, $\theta$ had a greater influence on EMh0.50 than ECe, indicating that $\theta$ had a large influence at L5. GW characteristics also showed relatively significant influences on EMh0.50 and EMv0.50, with rates of contribution of $21.45 \%$ and $17.16 \%$, respectively. DGW and ECGW showed negative correlations with ECa measured at a height of $0.50 \mathrm{~m}$, although the correlation was only significant for DGW $\left(\mathrm{R}=-0.58^{* *},-0.54^{* *}, \mathrm{P}<0.01\right)$, consistent with the study of Bouksila et al. (2012). 
Table 7. Path coefficients between influence factors to EM38 values at $0.50 \mathrm{~m}$ above the ground of $0.80 \sim 1.00 \mathrm{~m}$

\begin{tabular}{c|c|c|c|c|c|c|c|c}
\hline $\begin{array}{c}\text { Dependent } \\
\text { variable }\end{array}$ & Variable & ECe & $\boldsymbol{\theta}$ & $\boldsymbol{\gamma}$ & $\mathbf{E C G W}$ & $\mathbf{D G W}$ & $\begin{array}{c}\text { Contribution } \\
\text { rate }\end{array}$ & $\begin{array}{c}\text { Correlation } \\
\text { coefficient } \\
\text { with EM }\end{array}$ \\
\hline \multirow{3}{*}{ EMv0.50 } & $\mathbf{0 . 4 5 0 0}$ & 0.2682 & -0.0123 & 0.0043 & 0.0906 & $36.98 \%$ & $0.80^{* *}$ & $\mathbf{0 . 4 5 0 0}$ \\
& 0.2898 & $\mathbf{0 . 4 2 3 0}$ & -0.0254 & 0.0013 & 0.0890 & $34.76 \%$ & $0.78^{* *}$ & 0.2898 \\
& 0.0986 & 0.1916 & $\mathbf{- 0 . 0 5 6 0}$ & -0.0087 & 0.0044 & $4.60 \%$ & 0.23 & 0.0986 \\
& -0.0711 & -0.0207 & -0.0181 & $\mathbf{- 0 . 0 2 7 0}$ & -0.1138 & $2.22 \%$ & -0.25 & -0.0711 \\
& -0.1561 & -0.1442 & 0.0010 & -0.0118 & $\mathbf{- 0 . 2 6 1 0}$ & $21.45 \%$ & $-0.57^{* *}$ & -0.1561 \\
\hline & $\mathbf{0 . 4 2 9 1}$ & 0.3132 & -0.0339 & -0.0021 & 0.0784 & $32.58 \%$ & $0.78^{* *}$ & $\mathbf{0 . 4 2 9 1}$ \\
& 0.2721 & $\mathbf{0 . 4 9 4 0}$ & -0.0702 & -0.0006 & 0.0771 & $37.51 \%$ & $0.77^{* *}$ & 0.2721 \\
EMh0.50 & 0.0940 & 0.2238 & $\mathbf{- 0 . 1 5 5 0}$ & 0.0042 & 0.0038 & $11.77 \%$ & 0.17 & 0.0940 \\
& -0.0678 & -0.0242 & -0.0501 & $\mathbf{0 . 0 1 3 0}$ & -0.0985 & $0.99 \%$ & -0.23 & -0.0678 \\
& -0.1489 & -0.1685 & 0.0026 & 0.0057 & $\mathbf{- 0 . 2 2 6 0}$ & $17.16 \%$ & $-0.54^{* *}$ & -0.1489 \\
\hline
\end{tabular}

EMh0.50 - EM38 values of apparent electrical conductivity in horizontal operation mode; EMv0.50EM38 values of apparent conductivity in vertical operation mode; ECe - soil electrical conductivity; $\theta$ — soil moisture; $\gamma$ — soil clay content; ECGW—groundwater conductivity; DGW—groundwater level; *, ** significant at 0.05 and 0.01 level of probability, respectively. Bold font indicates direct path coefficient of corresponding factor

ECa measured by EM38 at a height of $0 \mathrm{~m}$ showed the best correlation with ECe at all soil layers (Huang et al., 2015; Yao and Yang, 2010). However, in the present study, the height of EM38 was set at $1.30 \mathrm{~m}, 1.10 \mathrm{~m}, 0.90 \mathrm{~m}, 0.70 \mathrm{~m}$ and $0.50 \mathrm{~m}$ in sequence, where the corresponding effective investigation depths were $0.20 \mathrm{~m}, 0.40 \mathrm{~m}, 0.60 \mathrm{~m}$, $0.80 \mathrm{~m}$ and $1.00 \mathrm{~m}$ respectively. This approach was taken to more directly analyze influences of soil properties on ECa in the different layers. The results showed that ECe had the greatest influence on EMv regardless of EM38 height, with the influences of $\theta$, DGW and ECGW increasing as EM38 height decreased, whereas the influence of clay content remained negligible. In general, soil $\mathrm{ECa}$ has been found to be mainly influenced by the factor showing the most spatial variability across the research region (Doolittle and Brevik, 2014). As a result, since $\gamma$ showed less spatial variability than that of soil ECe and $\theta$ in the vertical direction, the fact that $\gamma$ had a negligible effect on ECa was expected.

\section{Prediction of ECe in different soil layers}

Linear regression has been widely used to study the relationship between ECe and ECa of soil (Triantafilis et al., 2000; Bennett and George, 1995). In the present study, ECe of different soil layers was taken as the dependent variable and EMh and EMv were taken as the independent variables within simple linear regression analysis. ECe of different soil layers was then taken as the dependent variable and both EMh and EMv were taken as independent variables within binary linear regression analysis. Furthermore, the factors with large influences on ECa were gradually introduced as additional independent variables together with ECa to generate an MLR model for different soil layers. For all soil layers, $\theta$, DGW and ECGW were chosen as the additional independent variables and were gradually introduced into the prediction 
model. Figure 2 shows the change in $\mathrm{R}^{2}$ with the gradual addition of different variables into the prediction model. The optimal ECe interpretation models for different soil layers are shown in Table 2.

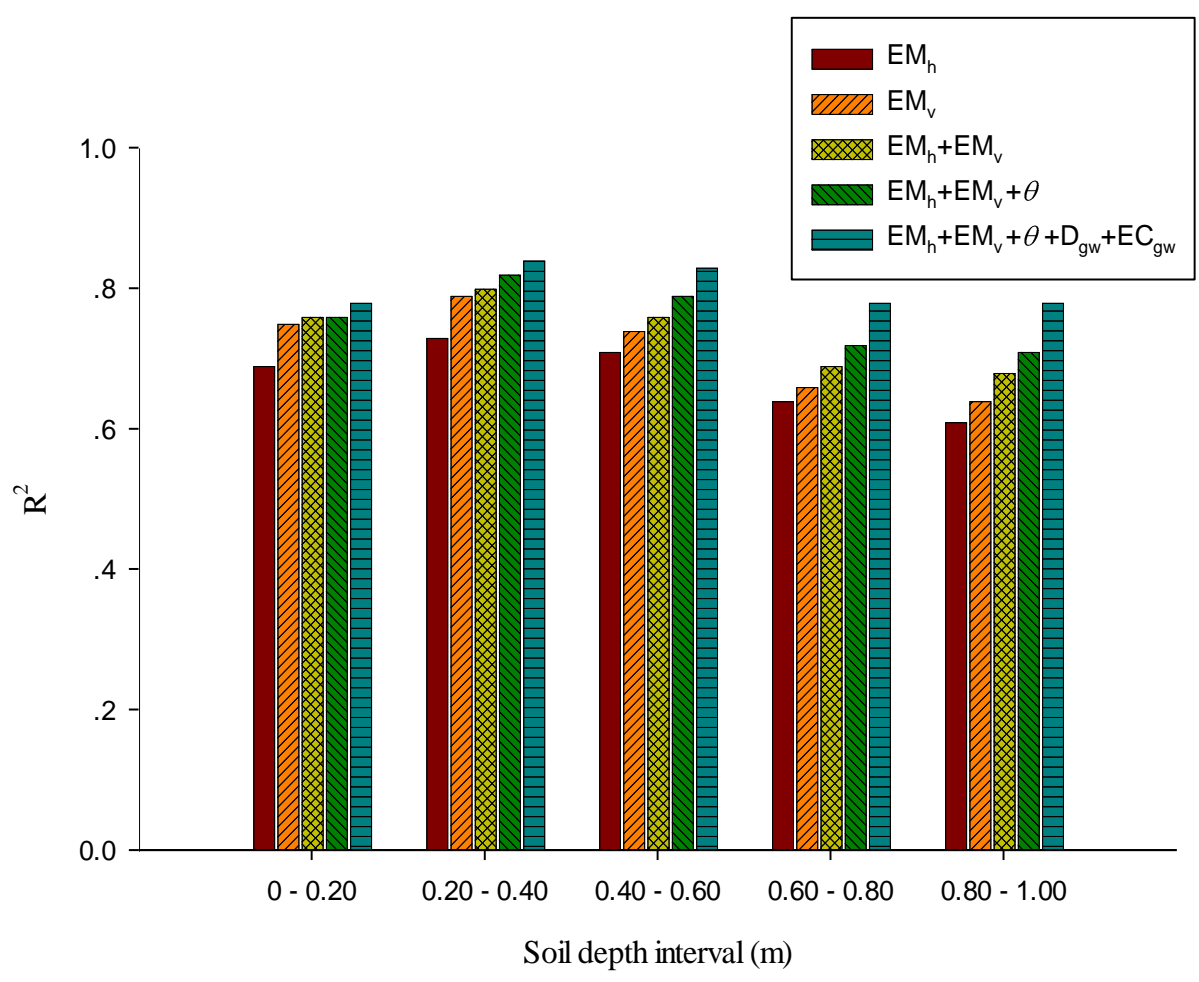

Figure 2. The change in $R^{2}$ with the gradual addition of different variables into the prediction

In general, at an EM38 height of $0 \mathrm{~m}$ and a separation of $1 \mathrm{~m}$ between the receiving coil and transmitting coil, the effective investigation depth was $0.75 \mathrm{~m}$ in the horizontal mode and $1.5 \mathrm{~m}$ in the vertical mode. Therefore, the correlation between ECe at the top soil layer and ECa measured in the horizontal mode was higher than that between ECe at the top soil layer and ECa measured in the vertical mode (Huang et al., 2015; Yao and Yang, 2010), whereas the correlation between ECe at the bottom soil layer and ECa measured in the vertical mode was higher than that between ECe at the bottom soil layer and ECa measured in the horizontal mode. In the present study, ECe values at different soil layers (L1-L5) were interpreted using ECa data measured at the corresponding heights $(1.30 \mathrm{~m}, 1.10 \mathrm{~m}, 0.90 \mathrm{~m}, 0.70 \mathrm{~m}$ and $0.50 \mathrm{~m}$, respectively). As shown in Figure 2, the effectiveness of EMv in providing an interpretation was better than that of EMh for all soil layers because at an EM38 height $<1.5 \mathrm{~m}$, soil information could be effectively investigated in the vertical mode, whereas this was only true for the horizontal mode at EM38 height $<0.75 \mathrm{~m}$. The prediction accuracy of ECe at L1 using EMv1.30 was low. On the other hand, the highest prediction accuracy of ECe using EMv1.10 was at L2. Below L2, the prediction accuracy of ECe decreased with increasing soil depth. A possible explanation is that since $\theta$ at $\mathrm{L} 1$ is low, some salt at $\mathrm{L} 1$ is likely to remain undissolved, thereby providing no contribution to the reading of EM38. In addition, with decreasing EM38 height, the thickness of the soil that can influence ECa increases; thus, the prediction accuracy of ECe using ECa within the deeper soil layer decreases. 
Various studies have used EM38 data in both the horizontal and vertical modes to interpret soil salt content, and ECe prediction models have been developed with relatively high accuracies (Liu et al., 2016; Lesch et al., 2000). As shown in Figure 1, the accuracy of the model developed in the present study improved with the incorporation of both EMh and EMv. However, with the use of EMh1.30 and EMv1.30 to interpret ECe at L1 and EMh1.10 and EMv1.10 to interpret ECe at L2, the improvement in the accuracy of the interpretation model was not as high as those in the other three cases. This observation can be explained by the fact that the effective investigation depth in the horizontal mode was only $0.75 \mathrm{~m}$. More specifically, at EM38 heights of $1.10 \mathrm{~m}$ or $1.30 \mathrm{~m}$, despite EMh showing an extremely significant correlation with ECe, ECe was in fact mainly influenced by EMv because the linear relationship between EMv and EMh could be identified during EM38 calibration. This explains why introducing EMh into the model did not increase the accuracy of the model for predicting salt content at L1 and L2.

Among all the factors that can influence soil $\mathrm{ECa}$ in salinized regions, the concentration of soluble salt is the most prominent (Williams et al., 2006). However, due to upward leaching and evaporative processes, GW salt tends to accumulate in the soil (Richardson and Williams, 1994). Liu et al (2010) showed $\theta$ and ECGW to be the most important non-salt factors in regions of relatively shallow GW. Therefore, the accuracy of the soil salt prediction model can be improved by introducing $\theta$ and ECGW into the model as additional independent variables. Similar conclusions were made in the present study. At L1, DGW and ECGW showed significant correlations with ECe $(\mathrm{P}<0.05)$, whereas $\theta$ did not. As a result, the introduction of $\theta$ into the model did not improve the model's accuracy, whereas the opposite was found with the introduction of GW characteristics ( $\mathrm{R}^{2}$ increased from 0.76 to 0.78 ). At $\mathrm{L} 2, \theta$ showed a significant correlation with $\gamma$ and DGW (P<0.05), indicating that $\theta$ at L2 is greatly affected by $\gamma$ and GW characteristics. With an increase in $\theta$, salt dissolved; thus, when $\theta$, ECGW and DGW were introduced into the prediction model, $\mathrm{R}^{2}$ increased from 0.80 to 0.84 . This was also observed at L3-L5, where the ECe prediction accuracies increased to 0.83, 0.78 and 0.78 respectively. Hanson and Kaita (1997) found a positive relationship between $\theta$ and the sensitivity of EM38 to variation in soil salt content. Therefore, when using EM38 to measure soil salt content, the influence of $\theta$ on ECa should be taken into account (Brevik et al., 2002). In the present study, incorporating $\theta$ improved the accuracy of the ECe prediction model except at L1. In addition, incorporating GW characteristics improved the model accuracy for the deeper soil layers to a larger degree than that for the top soil layer, possible due to the relatively shallow DGW in the research region.

\section{Validation of interpretation model for soil salt content}

Table 8 shows the models used to predict salt content in the different soil layers. The reserved 30 soil profiles were used as test data to validate the reliability of the models. The independent variables can be used by the prediction models to estimate salt content in the test profiles for different soil layers. By comparing the model predictions of salt content with laboratory measurements, the accuracy and practicability of the interpretation model can be validated.

Figure 3 shows the $\mathrm{R}^{2}$ values for the salt content predictions versus measurements in the test profiles of each layer. All values of $\mathrm{R}^{2}$ were greater than 0.70 , indicating highly significant correlations between the model predictions and the measurements. This 
demonstrated that the model represented major processes affecting salt content in the different layers relatively well. On the other hand, the values of ME between the predictions and the ECe measurements for L1-L5 were 0.63, 0.46, 0.53, 0.25 and 0.24 , respectively, whereas the values of RMSE were $0.77,0.48,0.21,0.26$ and 0.24 , respectively.
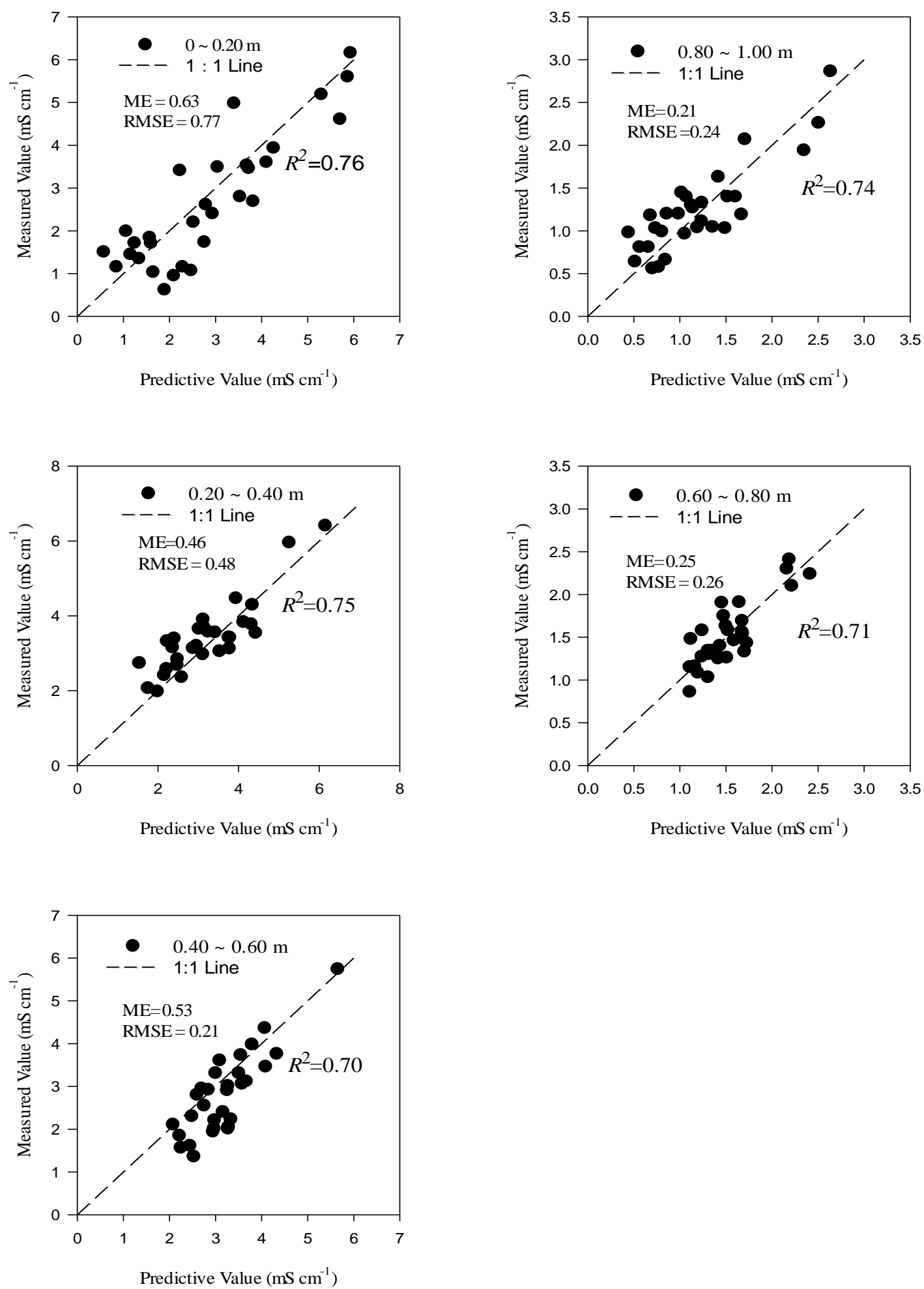

Figure 3. Fitting of soil EC between predicted value and measured value in different soil layers 
Table 8. The exact interpretation model of salt in different soil layers

\begin{tabular}{c|c|c}
\hline $\begin{array}{c}\text { Soil } \\
\text { layers }\end{array}$ & Model equation & $\mathbf{R}^{2}$ \\
\hline $0 \sim 20$ & $-0.317+0.035 \times \mathrm{EMv} 1.30+0.012 \times \mathrm{ECGW}-0.005 \times \mathrm{DGW}$ & 0.78 \\
$20 \sim 40$ & $0.142+0.013 \times \mathrm{EMv} 1.10-2.56 \times \theta+0.004 \times \mathrm{ECGW}+0.003 \times \mathrm{DGW}$ & 0.84 \\
$40 \sim 60$ & $-0.51+0.004 \times \mathrm{EMh} 0.90+0.01 \times \mathrm{EMv} 0.90+2.385 \times \theta+0.01 \times \mathrm{ECGW}+0.003 \times \mathrm{DGW}$ & 0.83 \\
$60 \sim 80$ & $-0.85+0.005 \times \mathrm{EMh} 0.70+0.002 \times \mathrm{EMv} 0.70+0.634 \times \theta+0.01 \times \mathrm{ECGW}+0.01 \times \mathrm{DGW}$ & 0.78 \\
$80 \sim 100$ & $-1.48+0.006 \times \mathrm{EMh} 0.50+0.001 \times \mathrm{EMv} 0.50-4.68 \times \theta+0.001 \times \mathrm{ECGW}+0.017 \times \mathrm{DGW}$ & 0.78 \\
\hline
\end{tabular}

\section{Conclusions}

Path analysis was used in the present study to analyze the influences of soil properties and GW characteristics in different soil layers on ECa as measured by EM38 at different heights. The results showed that ECe was the most important factor influencing ECa measured at different heights. The rates of contribution of ECe to EMv at L1-L5 were $65.78 \%, 82.21 \%, 65.79 \%, 49.26 \%$ and $36.98 \%$, respectively. The results showed that the degree of influence of the bottom soil layer to ECa decreased whereas those of other soil properties increased with increasing soil depth. In addition, since $\theta$ at L1 was relatively low, the rate of contribution of ECe to ECa at L1 was also relatively small. The influence of $\theta$ on ECa was also noticeable, with rates of contribution to ECa at L1-L5 being $10.93 \%, 7.85 \%, 9.15 \%, 16.64 \%$ and $34.76 \%$, respectively. The rates of contribution of DGW to ECa measured by EM38 at heights of $1.30 \mathrm{~m}, 1.10 \mathrm{~m}, 0.90 \mathrm{~m}$, $0.70 \mathrm{~m}$ and $0.50 \mathrm{~m}$ were $4.67 \%, 5.27 \%, 10.64 \%, 22.62 \%$ and $21.45 \%$, respectively, whereas those of ECGW were $9.27 \%, 4.47 \%, 12.75 \%, 11.07 \%$ and $2.22 \%$, respectively. In arid and semi-arid areas, due to upward leaching and evaporative processes, GW salt tends to accumulate in the soil. In such areas, the soil salt content has significant correlations with unsuitable irrigation practices, evapotranspiration of farm land and DGW during crop growth. GW characteristics impose an influence on ECa by influencing ECe in each layer. In the research region, the influence of $\gamma$ on the ECa was minor.

Linear regression was used to derive optimal ECe prediction models for different soil layers. Taking ECe of different soil layers as the dependent variable and EMh and EMv as the independent variables in sequence, simple linear regression analysis was conducted. Binary linear regression analysis was conducted by taking ECe of different soil layers as the dependent variable and both EMh and EMv as the independent variables. $\theta$, DGW and ECGW were then gradually introduced into the prediction model as additional independent variables. The results showed EMv to provide a better interpretation than EMh in each soil layer. This was because at an EM38 height $<1.5 \mathrm{~m}$, the soil information could be effectively investigated in the vertical mode, whereas this was only true for the horizontal mode at an EM 38 height $<0.75 \mathrm{~m}$. The ECe prediction accuracy at L1 using EMv1.30 was low due to low $\theta$. On the other hand, the ECe prediction accuracy at L2 was the highest; however, as the depth of the soil layer increased below L2, the ECe prediction accuracy decreased. When EMh and EMv were both used to derive the interpretation model, the model accuracy improved.

$\theta$ and GW characteristics were important factors influencing $\mathrm{ECa}$; therefore, their influences on ECa need to be considered when using EM38 to measure soil salt content. With the introduction of $\theta$ and GW characteristics to the prediction model as additional independent variables, the reliability of the ECe prediction model in each soil layer 
improved. In addition, the addition of GW characteristics improved the prediction accuracy for the bottom soil layer more than that for the top soil layer.

The accuracies of the ECe prediction models for different soil layers were validated. $\mathrm{R}^{2}$ values showing the correlations between model ECe predictions and measurements of each layer were $>0.70$. ME and RMSE values at L1-L5 were 0.63, 0.46, 0.53, 0.25 and 0.24 , respectively, and $0.77,0.48,0.21,0.26$ and 0.24 , respectively. The results suggested that the models for L3-L5 were more accurate than those for L1-L2.

The EMI approach offers potential for improving the prediction accuracy of soil salinity information by the addition of influence factors into the multiple regression model. In the future research, it is necessary to study the denoising of data to help resolve some of the uncertainty issues associated with this non-contacting technology and further improve the accuracy of the interpretation model.

Acknowledgements. The authors are grateful for the financial support of the International Science \& Technology Cooperation Program of China [grant number 2015DFA11660], Major Scientific Research Projects of Xinjiang Production and Construction Corps (2018AA004, 2018AA005). We would also like to thank the reviewers for their time spent in improving the paper.

\section{REFERENCES}

[1] Abdu, H., Robinson, D. A., Jones, S. B. (2007): Comparing bulk soil electrical conductivity determination using the DUALEM 1-S and EM-38DD EMI instruments. Soil Science Society of America Journal 71(1): 189-196.

[2] Aboelsoud, H., Abdel-Rahman, M. (2017): Rapid field technique for soil salinity appraisal in north Nile delta using EM38 through some empirical relations. International Journal of Plant \& Soil Science 14: 1-9.

[3] Bekele, A., Hudnall, W. H., Daigle, J. J., Prudente, J. A., Wolcott, M. (2005): Scale dependent variability of soil electrical conductivity by indirect measures of soil properties. - Journal of Terramechanics 42(3-4): 339-351.

[4] Bennett, D. L., George, R. J. (1995): Using the em38 to measure the effect of soil salinity on Eucalyptus globulus, in South-Western Australia. - Agricultural Water Management 27(1): 69-85.

[5] Bennett, D. L., George, R. J., Whitfield, B. (2000): The use of ground EM systems to accurately assess salt store and help define land management options, for salinity management. - Exploration Geophysics 31(1/2): 249-254.

[6] Bouksila, F., Persson, M., Bahri, A., Berndtsson, R. (2012): Electromagnetic induction prediction of soil salinity and groundwater properties in a Tunisian Saharan oasis. Hydrological Sciences Journal 57(7): 1473-1486.

[7] Brevik, E. C., Fenton, T. E. (2002): Influence of soil water content, clay, temperature, and carbonate minerals on electrical conductivity readings taken with an EM-38. - Soil Horizons 43(1): 9-13.

[8] Brevik, E. C., Fenton, T. E., Horton, R. (2004): Effect of daily soil temperature fluctuations on soil electrical conductivity as measured with the Geonics ${ }^{\circledR}$ EM-38. Precision Agriculture 5(2): 145-152.

[9] Butcher, K., Wick, A. F., DeSutter, T., Chatterjee, A., Harmon, J. (2016): Soil salinity: a threat to global food security. - Agronomy Journal 108(6): 2189-2200.

[10] Cassel, F., Goorahoo, D., Sharmasarkar, S. (2015): Salinization and yield potential of a salt-laden Californian soil: an in situ geophysical analysis. - Water, Air, \& Soil Pollution 226(12): 422. 
[11] Cook, P. G., Walker, G. R. (1992): Depth profiles of electrical conductivity from linear combinations of electromagnetic induction measurements. - Soil Science Society of America Journal 56(4): 1015-1022.

[12] Corwin, D. L., Rhoades, J. D. (1982): An improved technique for determining soil electrical conductivity-depth relations from above-ground electromagnetic measurements 1. - Soil Science Society of America Journal 46(3): 517-520.

[13] Dakak, H., Huang, J., Zouahri, A., Douaik, A., Triantafilis, J. (2017): Mapping soil salinity in 3 - dimensions using an EM38 and EM4Soil inversion modelling at the reconnaissance scale in central Morocco. - Soil use and management 33(4): 553-567.

[14] Ding, J., Yu, D. (2014): Monitoring and evaluating spatial variability of soil salinity in dry and wet seasons in the Werigan-Kuqa Oasis, China, using remote sensing and electromagnetic induction instruments. - Geoderma 235: 316-322.

[15] Doolittle, J. A., Brevik, E. C. (2014): The use of electromagnetic induction techniques in soils studies. - Geoderma 223: 33-45.

[16] Doolittle, J. A., Indorante, S. J., Potter, D. K., Hefner, S. G., McCauley, W. M. (2002): Comparing three geophysical tools for locating sand blows in alluvial soils of southeast Missouri. - Journal of Soil and Water Conservation 57(3): 175-182.

[17] Liu, G., Yang, J., Yao, R. (2010): Electromagnetic induction based interpreting model of soil salinity in different soil layers. - Transactions of the Chinese Society of Agricultural Engineering 26(1): 61-66.

[18] Han, D., Song, X., Currell, M. J., Cao, G., Zhang, Y., Kang, Y. (2011): A survey of groundwater levels and hydrogeochemistry in irrigated fields in the Karamay Agricultural Development Area, Northwest China: implications for soil and groundwater salinity resulting from surface water transfer for irrigation. - Journal of Hydrology 405(3-4): 217234.

[19] Hanson, B. R., Kaita, K. (1997): Response of electromagnetic conductivity meter to soil salinity and soil-water content. - Journal of irrigation and Drainage Engineering 123(2): 141-143.

[20] He, Y., Desutter, T., Norland, J., Chatterjee, A., Casey, F., Clay, D. (2018): The measurement, prediction, and development of soil management zones in low-relief sodic soils. - Precision Agriculture 1-18.

[21] Heil, K., Schmidhalter, U. (2017): The application of em38: determination of soil parameters, selection of soil sampling points and use in agriculture and archaeology. Sensors 17(11): 2540.

[22] Hossain, M. B., Lamb, D. W., Lockwood, P. V., Frazier, P. (2010): Em38 for volumetric soil water content estimation in the root-zone of deep vertosol soils. - Computers \& Electronics in Agriculture 74(1): 100-109.

[23] Huang, J., Purushothaman, R., McBratney, A., Bramley, H. (2018): Soil water extraction monitored per plot across a field experiment using repeated electromagnetic induction surveys. - Soil Systems 2(1): 11.

[24] Jadoon, K. Z., Moghadas, D., Jadoon, A., Missimer, T. M., Al-Mashharawi, S. K., McCabe, M. F. (2015): Estimation of soil salinity in a drip irrigation system by using joint inversion of multicoil electromagnetic induction measurements. - Water Resources Research 51(5): 3490-3504.

[25] Jiang, Z. Y., Li, X. Y., Wu, H. W., Zhang, S. Y., Zhao, G. Q., Wei, J. Q. (2017): Linking spatial distributions of the patchy grass Achnatherum splendens with dynamics of soil water and salt using electromagnetic induction. - Catena 149: 261-272.

[26] Kasim, N., Tiyip, T., Abliz, A., Nurmemet, I., Sawut, R., Maihemuti, B. (2018): Mapping and modeling of soil salinity using WorldView-2 data and EM38-KM2 in an arid region of the Keriya River, China. - Photogrammetric Engineering \& Remote Sensing 84(1): 4352 . 
[27] Krajco, B. J. (2007): Detection of soil compaction using soil electrical conductivity. Journal of Physical Chemistry A 111(34): 8352-8356.

[28] Lesch, S. M., Corwin, D. L. (2003). Using the dual-pathway parallel conductance model to determine how different soil properties influence conductivity survey data. Agronomy Journal 95(2): 365-379.

[29] Lesch, S. M., Rhoades, J. D., Corwin, D. L. (2000): ESAP-95 Version 2.01 R: User manual and tutorial guide. - Research Rpt. 146, USDA-ARS George E. Brown, Jr. Salinity Laboratory, Riverside, CA.

[30] Li, J. G., Pu, L. J., Han, M. F., Zhu, M., Zhang, R. S., Xiang, Y. Z. (2014): Soil salinization research in China: advances and prospects. - Journal of Geographical Sciences 24(5): 943-960.

[31] Liu, G. M., Li, J. B., Zhang, X. C., Wang, X. P., Lv, Z. Z., Yang, J. S., Shao, H. B., Yu, S. P. (2016): GIS-mapping spatial distribution of soil salinity for Eco-restoring the Yellow River Delta in combination with electromagnetic induction. - Ecological Engineering 94: 306-314.

[32] Mankin, K. R., Karthikeyan, R. (2002): Field assessment of saline seep remediation using electromagnetic induction. - Transactions of the ASAE 45(1): 99.

[33] Martinez, G., Vanderlinden, K., Ordóñez, R., Muriel, J. L. (2009). Can apparent electrical conductivity improve the spatial characterization of soil organic carbon?. - Vadose Zone Journal, 8(3), 586-593.

[34] McKenzie, R. C., Mathers, H. M., Robertson, J. M., Woods, S. A. (1993). Salinity and cold tolerance of ornamental trees and shrubs. - Alberta Special Crops and Horticultural Research Center.

[35] McNeill, J. D. (1980): Electromagnetic terrain conductivity measurement at low induction numbers. - Geonics Limited, Mississauga, ON, Canada.

[36] McNeill, J. D. (1990): Geonics EM38 ground conductivity meter: EM38 operating manual. - Geonics Ltd., Mississauga, ON, Canada.

[37] Misra, R. K., and Padhi, J. (2014): Assessing field-scale soil water distribution with electromagnetic induction method. - Journal of Hydrology 516: 200-209.

[38] Norman, C. P. (1990): Training manual on the use of the EM38 for soil salinity appraisal. - Victorian Department of Agriculture and Rural Affairs, Australia.

[39] Rahimian, M. H., Hasheminejhad, Y. (2011): Calibration of electromagnetic induction device (EM38) for soil salinity assessment. - Iranian Journal of Soil Research 24(3): 243252.

[40] Rengasamy, P. (2006): World salinization with emphasis on Australia. - Journal of Experimental Botany 57(5): 1017-1023.

[41] Richardson, D. P., Williams, B. G. (1994): Assessing discharge characteristics of upland landscapes using electromagnetic induction techniques. - CSIRO, Canberra.

[42] Scudiero, E., Skaggs, T. H., Corwin, D. L. (2016). Comparative regional-scale soil salinity assessment with near-ground apparent electrical conductivity and remote sensing canopy reflectance. - Ecological indicators, 70, 276-284.

[43] Silberstein, R. et al. (2007): Does grazing perennial pastures on saline land affect farm salt and water balances? - SGSL Salt and Water Movement Theme Report. http://www.saltlandgenie.org.au/ literature_ 23944/RR — _SGSL_ Salt_and Water Movement and Site Characterisation Theme (Accessed 14 August 2012).

[44] Singh, A. (2018): Use of em-38 soil surveys in forage fields at a saline drainage water reuse site to calibrate a hydro-salinity model for decision support. - A thesis submitted in partial fulfillment of the requirements for the degree of Master of Science in Plant Science in the Jordon College of Agricultural Sciences and Technology California State University, Fresno.

[45] Sudduth, K. A., Kitchen, N. R., Wiebold, W. J., Batchelor, W. D., Bollero, G. A., Bullock, D. G. et al. (2005): Relating apparent electrical conductivity to soil properties 
across the North-Central USA. - Computers and Electronics in Agriculture 46(1): 263283.

[46] Triantafilis, J., Laslett, G. M., Mcbratney, A. B. (2000): Calibrating an electromagnetic induction instrument to measure salinity in soil under irrigated cotton. - Soil Science Society of America Journal 64(3): 1009-1017.

[47] Triantafilis, J., Lesch, S. M. (2005): Mapping clay content variation using electromagnetic induction techniques. - Computers and Electronics in Agriculture 46(13): 203-237.

[48] Triantafilis, J., Santos, F. M. (2010): Resolving the spatial distribution of the true electrical conductivity with depth using EM38 and EM31 signal data and a laterally constrained inversion model. - Soil Research 48(5): 434-446.

[49] Williams, B., Walker, J., Anderson, J. (2006): Spatial variability of regolith leaching and salinity in relation to whole farm planning. - Australian Journal of Experimental Agriculture 46(10): 1271-1277.

[50] Wittler, J. M., Cardon, G. E., Gates, T. K., Cooper, C. A., Sutherland, P. L. (2006): Calibration of electromagnetic induction for regional assessment of soil water salinity in an irrigated valley. - Journal of Irrigation and Drainage Engineering 132(5): 436-444.

[51] Yao, R., Yang, J. (2010): Quantitative evaluation of soil salinity and its spatial distribution using electromagnetic induction method. - Agricultural Water Management 97(12): 1961-1970. 